\title{
The Similar Faces of Swiss Working Poor
}

\section{An Empirical Analysis Across Swiss Regions Using Logistic Regression and Classification Trees}

\author{
Fabio B. Losa and Emiliano Soldini ${ }^{\mathrm{b}}$
}

JEL-Classification: I32, J3.

Keywords: working poor, classification trees, logistic regression.

\section{Introduction}

Are the determinants of working poverty the same across Swiss regions? Does the phenomenon primarily affect similar social groups from Zurich to Ticino and from the Lake Geneva Region to Eastern Switzerland? Or are there significant regional peculiarities in terms of risk factors and/or groups, calling for regional policies?

The present paper - an empirical investigation into working poverty across the seven statistical regions in Switzerland - aims at providing answers to these questions by analysing the determinants of working poverty and by detecting the key characteristics of the population groups at major risk.

Considering that at the bottom of the emergence of this social problem many see the rise of labour flexibility in the context of globalization and of the principle changes affecting labour markets, comparative empirical evidence is certainly a crucial element for policy design, especially in a federal system like Switzerland.

Acknowledging that in order to assist policymakers in understanding and eventually defining suitable intervention measures it is of primary concern to be able to convey empirical evidence in a way which is both satisfying and easily understandable, two different multivariate statistical methods - logistic regression and classification trees - are applied in the analysis of the data. Due to their

a Statistical Office of the Ticino Canton, Bellinzona (Switzerland) and Center for Research in Economics and Management, University of Rennes 1; Rennes (France); fabio.losa@ti.ch.

b Department of Business Management and Social Work of the University of Applied Sciences of Southern Switzerland, Manno (Switzerland); emiliano.soldini@supsi.ch. 
complementary characters, the combined use of these methods will prove very efficient in bringing research evidence closer to policy needs.

The phenomenon of the working poor has come to attention in Switzerland since the economic slowdown of the 90s. The national report on poverty by LeU, Burri and Priester (1997) is considered, except for some initial contributions (most of them at cantonal level), the first milestone for research on the topic. This report was followed by a series of studies which specifically tackle the issue of the working poor (e.g. Deutsch, FlüCriger and Silber, 1999; Streuli and BAUER, 2002). The present paper contributes, through its comparative and methodological approach, to this stream of research.

The paper is organised into different sections. Following this introduction, section two tackles the question of defining working poverty, highlighting the complexity of this task and the resulting wide variety of definitions across countries and across different studies. It also describes the operational definition adopted by the Swiss Federal Statistical Office (FSO), which is the one used in the empirical analysis. Section three presents the data, the models and the methodological approach. Section 4 is devoted to the results of the empirical applications. As a conclusion, the paper assesses the results in the light of implications for policymaking.

\section{Defining Working Poverty}

\subsection{A Complex Concept Leading to Multiple Definitions}

Despite the fact that nowadays the phenomenon of working poverty is of great concern in several countries, there is still no common operational definition. This situation poses serious limits to comparability across studies and across countries. ${ }^{1}$

The whole issue is a matter of defining working and poverty, and a matter of how these two aspects are to be combined. ${ }^{2}$ Concerning the working population, the issue is related to which part of the population is considered (only the employed or the whole labour force ${ }^{3}$ ) and how employment intensity is considered

1 See Sharpe (2001) for an attempt in this direction.

2 See for example EFILWC (2004), Streuli and Bauer (2002) and Evans and Chawla (1990).

3 For this a better (and sometimes used) term is "active poor". 
in terms of relevant unit (individual person vs. working household), measures (number of hours worked per period or number of months in a year spent working regardless of the hours worked, or combinations of these measures), and threshold (from restrictive definitions considering only full-time and full-year employment, to more flexible ones including, for example, part-time work).

The spectrum of approaches for measuring poverty is widely known (objective vs. subjective, monetary vs. non monetary, relative vs. absolute, etc.); it is, however, worth recalling the fact that the relevant reference unit is the household, and that poverty is not just a matter of a person's own income, but also of the size and composition of the family, as well as all other family income sources, such as earnings from other family members and/or from other sources (capital income, social benefits, etc.).

Finally, the way in which working and poverty are linked to a conceptual and operational framework can take place at a personal level (i.e. a working poor is a worker living in a poor household), or at household level ${ }^{4}$.

\subsection{The FSO Definition}

According to the definition adopted in its annual statistics, FSO considers as working poor those people aged between 20 and 59 years who are working and live in a poor household.

In this respect:

1. A person is considered to belong to the working population if he/she has worked for at least one hour a week (during the survey week), and if, at the same time, he/she lives in a household whose total weekly number of hours worked is at least 36. In other words, the working population covers only those (working) persons living in households where the sum of the weekly hours worked by each member amounts to at least a full-time job (90\% or more of the normal weekly workload).

2. All the persons belonging to the working population are then assessed in terms of their household poverty/non poverty status. A household is poor when its disposable income - income after taxes and social security contributions lies below the poverty line defined for the specific type of household by the Swiss Conference for Social Aid and Welfare (CSAW) ${ }^{5}$. These widely accepted

4 This second option is rarely used, because for many purposes what is needed are figures and statistics on a personal basis (Evans and Chaw La, 1990).

5 In French Conférence Suisse des Instutions d'Action Sociale (CSIAS); in German Schweizerische Konferenz für Sozialhilfe (SKOS). 
administrative standards set the poverty line - calculated by adding the cost of a "moderate" rent and that of a basic health insurance premium to the CSAW's vital minimum - at 2,200 Swiss francs for a one-person household and at 4,640 for a couple with two children. ${ }^{6}$

It should be noted that, particularly with regard to the condition of working, the FSO definition can be considered quite restrictive, since it covers neither the unemployed nor the households working part-time. Moreover, the period of the survey reference week is the only basis used to determine the weekly minimum amount of hours worked.

From the point of view of the poverty threshold, it should be underlined that the CSAW standards are often adopted in Swiss studies on poverty, due to the fact that they are computed from the thresholds used by the public social services to determine whether a person (or a household) has the right to receive social assistance.

\section{Data and Methods}

\subsection{The Data}

The dataset used in this analysis was compiled by FSO on the basis of the 2006 Swiss Labour Force Survey (SLFS).

The SLFS is a survey conducted by phone and concerning approximately 48,000 households. Its basic population is the permanent resident population aged 15 years and over. The main purpose of the SLFS is to provide information on the structure of the labour force and employment behaviour patterns. The information gathered concerns: employment, reasons for remaining economically inactive (retirement, education or training, etc.), educational background and profession, place of work, work volume (in hours), working conditions (work schedule, night shift, work over the weekends), economic branch, job income, household income, jobseeker (unemployed, underemployed). The survey was carried out for the first time in 1991 and, due to a significant sample increase in 2001, since 2002 it is representative also at a regional level (European NUTS 2 regions).

6 The equivalence scales implicit in the CSAW norms are so-called "expert scales". It has been demonstrated that they are consistent with scales estimated by other scholars for Switzerland (for details see Falter, 2006). 
According to the population considered in the FSO definition, the sample sizes of the seven Swiss regions are the following: the Lake Geneva Region $(3,090)$, Espace Mittelland (2,577), Northwestern Switzerland (1,862), Zurich $(2,154)$, Eastern Switzerland (1,764), Central Switzerland $(1,406)$ and Ticino $(1,262){ }^{?}$

\subsection{The Variables Considered}

The dependent variable is binary, i.e. the person is either a working poor or not. The explanatory variables are a subset of the information collected in the SLFS database, containing those factors which, from bivariate analyses and evidence collected in previous studies (Crettaz and Farine, 2008; Losa and Soldini, 2006; Streuli and Bauer, 2002), appear to be connected to the occurrence of working poverty. These are (categorical or scale) variables related to the personal demographic and socioeconomic characteristics and to the household characteristics, as detailed in Table 1.

\subsection{The Methods}

The analysis is performed using two different multivariate statistical methods: logistic regression and classification trees. While the first method is largely used in the economic field, this is not the case for the second one, despite its broad (and growing) field of application. For this reason a brief explanation of classification trees follows.

Classification trees are similar to cluster analysis, but here the split of the initial population into several subgroups on the basis of a set of predictors is "driven" by a known (dependent) outcome variable (FABBRIs, 1997). A tree is built through a recursive partitioning process of splitting the data into groups, and then splitting it up further on each of the branches. At each step the algorithm considers each predictor in turn and chooses the best one, i.e. that which gives the most discriminant split between groups according to the outcome variable and a given rule. At each branch, the iterative process ends when a stopping rule is reached.

7 The Lake Geneva Region comprises the following Cantons: Vaud, Valais, Geneva; Espace Mittelland: Berne, Fribourg, Solothurn, Neuchâtel, Jura; Northwestern Switzerland: BaselCountry, Basel-City, Aargau; Zurich: Zurich; Eastern Switzerland: Glarus, Schaffhausen, Appenzell Innerrhoden, Appenzell Ausserrhoden, St. Gallen, Grisons, Thurgau; Central Switzerland: Lucerne, Uri, Schwyz, Obwalden, Nidwalden, Zug; Ticino: Ticino. 
Table 1: List of Selected Variables

\begin{tabular}{|c|c|c|}
\hline Variables & Type & Definition \\
\hline Sex & categorical & Male, Female \\
\hline Nationality & categorical & Foreigner, Swiss \\
\hline Age & scale & $20-59$ \\
\hline $\begin{array}{l}\text { Household labour } \\
\text { supply }\end{array}$ & scale & $\begin{array}{l}\text { Amount of weekly worked hours by all members of } \\
\text { the HH }\end{array}$ \\
\hline Household size & scale & Number of HH members \\
\hline Type of household & categorical & $\begin{array}{l}1 \text { person } \mathrm{HH} \text {, Lone parent } \mathrm{HH} \text {, Couple with, Couple } \\
\text { without children, Other }\end{array}$ \\
\hline Education & categorical & Elementary level, Intermediate, High \\
\hline Work experience & categorical & $\begin{array}{l}\text { Less than } 1 \text { month, } 1-5,6-11,1-2 \text { years, } 3-4,5 \text { years } \\
\text { or more }\end{array}$ \\
\hline $\begin{array}{l}\text { Duration of employ- } \\
\text { ment in current firm }\end{array}$ & categorical & $\begin{array}{l}\text { Less than } 1 \text { month, } 1-5,6-11,1-2 \text { years, } 3-4,5 \text { years } \\
\text { or more }\end{array}$ \\
\hline Economic activity & categorical & Primary Sector, Secondary, Tertiary \\
\hline Status in employment & categorical & $\begin{array}{l}\text { Chief executive, Employee with, Employee without } \\
\text { managerial functions }\end{array}$ \\
\hline Degree of employment & categorical & Part-time, Full-time worker \\
\hline Contract duration & categorical & Contract of limited, Contract of unlimited duration \\
\hline Job on call & categorical & Job on call, Not \\
\hline Working moments & categorical & $\begin{array}{l}\text { Working in the evening, at night or during the week- } \\
\text { end, Not }\end{array}$ \\
\hline $\begin{array}{l}\text { Type of weekly work- } \\
\text { ing time }\end{array}$ & categorical & $\begin{array}{l}\text { Fixed number of hours worked per week, Variable } \\
\text { number }\end{array}$ \\
\hline
\end{tabular}

The following example will clarify the procedure. Suppose that we want to investigate how the occurrence of cardiovascular diseases is affected by a family history of cardiovascular problems and systolic blood pressure. Supposing as well that the cardiovascular diseases status is a binary variable (suffering from cardiovascular diseases or not), the history of family cardiovascular problems may be measured by a categorical variable having three levels (low risk, intermediate risk and high risk), while systolic blood pressure (BP) is a continuous variable. Finally, suppose that we have a sample of 1,000 persons, 110 of whom suffer from cardiovascular diseases. One of the possible classification trees that could be obtained in such a situation is shown in Figure 1. 
Figure 1: Classification Tree

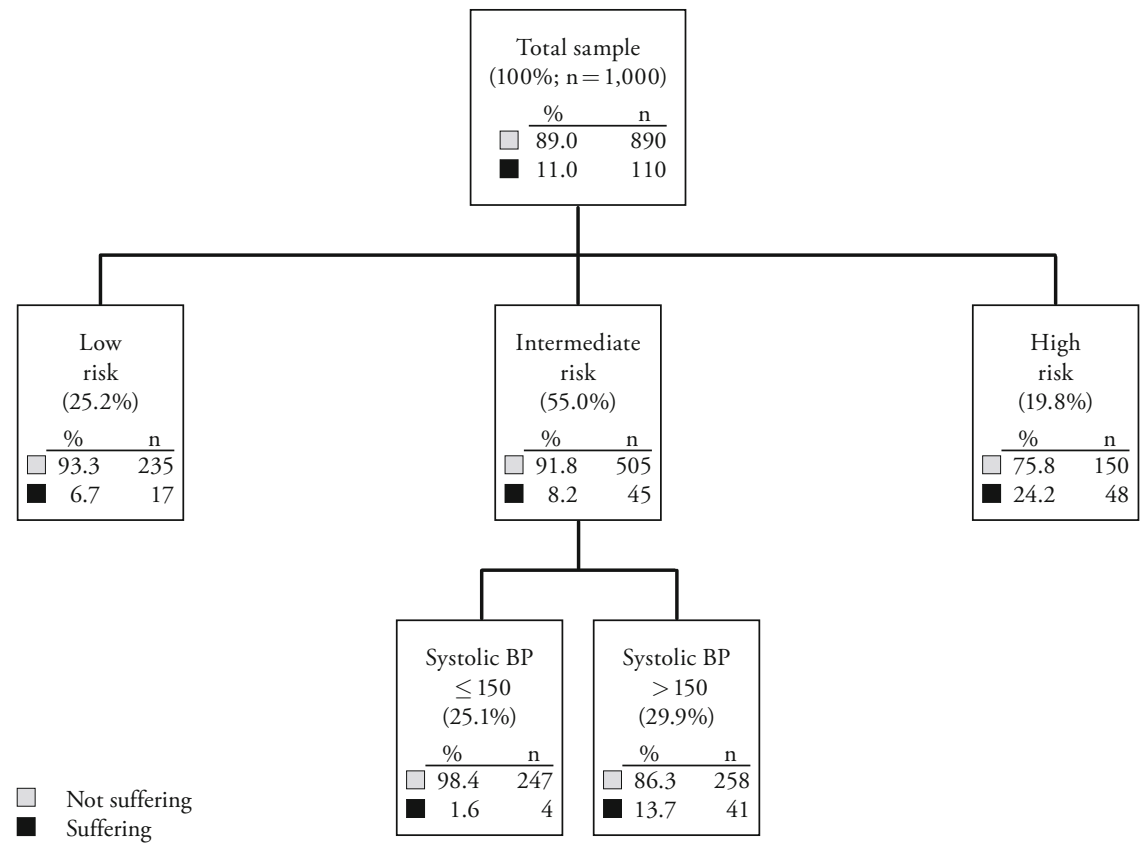

The starting point of the tree (the first node) shows the total sample size and the partition of the outcome variable within the sample. Starting from the first node, the chosen algorithm ${ }^{8}$ identifies the predictor that gives the most discriminant split according to the partition of the cardiovascular disease status, which, in this case, is the family history of cardiovascular problems. The boxes representing the resulting subgroups indicate what predictor has been retained at that stage as well as the percentage of the sample and the outcome variable partition for each subgroup. Then, the described procedure is repeated for every subgroup until a stopping rule is reached. It is important to underline that at each node the algorithm again tests

8 In this article the chosen algorithm is called CHAID (KAss, 1980) and is supported by Answer Tree (a module of SPSS); we chose it in order to obtain not only binary ramifications. This algorithm uses the degree of statistical significance of the $\mathrm{Chi}^{2}$ independence test to choose which predictor gives the most discriminant split of the data with respect to the partition of the outcome variable. 
all the predictors, which means that a predictor could appear more than once in a given tree. The second split, concerning the systolic blood pressure, indicates that continuous variables may also be used in this kind of analysis. When a given node does not generate any further ramification, it is because one of the thresholds set by the stopping rules has been met, i.e. maximum tree depth, minimum number of cases for parent node, minimum number of cases for child nodes or no more significant predictors according to the Chi-square independence test ${ }^{9}$. Of course, the size (and richness) of the tree strongly depends on the stopping rules: setting relatively loose stopping rules will lead to very rich trees, while narrow stopping rules will result in essential and short trees. Since for this application trees are not used for their (more common) predictive usage but as a descriptive tool, we intentionally define relatively loose stopping rules in order to achieve a very rich picture concerning the interaction of the determinants of working poverty.

\section{Empirical Results}

\subsection{Determinants of Working Poverty}

Despite the many social, political and economic differences, stemming from differing cultures and various institutional and political settings, which exist within the Swiss Confederation, and despite differing working poor rates (see Table 2), the primary risk factors for working poverty are the same in all the seven Swiss regions. These are household size, household labour supply, educational level and nationality. In logistic regressions they are all highly significant; in classification trees they always appear at the first levels of the trees, highlighting their crucial discriminant power.

Table 2: Working Poor Rates in the Seven Swiss Regions ${ }^{10}$

\begin{tabular}{lcccccccc}
\hline & Lake & Espace & North- & & & & \\
western & & Eastern & Central & \\
& $\begin{array}{c}\text { Geneva } \\
\text { Region }\end{array}$ & $\begin{array}{c}\text { Mittel- } \\
\text { land }\end{array}$ & $\begin{array}{c}\text { Switzer- } \\
\text { land }\end{array}$ & Zurich & $\begin{array}{c}\text { Switzer- } \\
\text { land }\end{array}$ & $\begin{array}{c}\text { Switzer- } \\
\text { land }\end{array}$ & Ticino \\
\hline Working poor rates & $4.7 \%$ & $4.2 \%$ & $4.4 \%$ & $4.2 \%$ & $4.4 \%$ & $4.7 \%$ & $7.1 \%$ \\
\hline
\end{tabular}

9 The threshold value concerning the $\mathrm{Chi}^{2}$ independence test is set at $5 \%$ confidence level.

10 Courtesy of Mr Eric Crettaz (SFO). 
Other factors appear to have a significant relationship to working poverty; these are, however, more specific to single regions.

The results of logistic regressions highlight a set of employment factors for four of the seven regions - professional inexperience, recently employed by the current firm, employee without managerial functions, variable number of hours worked per week - which are statistically significant and logically highly correlated. These convey the idea of a fifth cross-regional factor related to employment at a low salary. The remaining regional variables, according to logistic regressions, are two types of household which occasionally emerge.

Trees substantially confirm these findings by putting the additional factors from the third level of the trees so that they concur, as we will see in the next subchapter, in identifying subgroups of combinations of the first four determinants.

Mean marginal effects of the logistic regressions (Table 3) show signs of the relationships with working poverty which are consistent with the basic hypotheses; the same is true for the partitions emerging in classification trees. At the same time, the sizes of mean marginal effects highlight, here and there, relevant regional differences.

Further relevant details:

- The probability of falling below the poverty line is positively related ceteris paribus to household size: independently of the region considered, an additional member in the household has on average the effect of increasing the risk of being working poor by from two to three percentage points. Only Ticino is an exception with almost four percentage points. ${ }^{11}$

- The more the members of a household work, the lower is the relative likelihood of them being working poor: an increase in the total household employment by a part-time job with a degree of employment of around 50\% (an additional 20 hours a week) reduces - other factors remaining unchanged - the probability of falling below the poverty line by an amount of between two percentage points (Espace Mittelland) and almost six percentage points (Ticino).

- Educational level is negatively related to the probability of falling below the poverty line, since it is a factor that improves labour productivity, and therefore increases the chances of having a better job (in terms of earnings and conditions). The mean marginal effects show relevant cross-regional differences:

11 The magnitude of the effects of household size and type depend ultimately on the equivalence scales of the CSAW norms. Considering the works of FALTER (2006), the impacts could be somewhat overestimated. 
education plays a more minor role in Ticino and Espace Mittelland than in the other regions.

- Nationality shows quite relevant cross-regional differences: foreigners have (ceteris paribus) probabilities of falling below the poverty line which are between 2.5 (Eastern Switzerland) and 5.2 percentage points (Ticino) higher than those for Swiss employees.

\subsection{Groups at Major Risk}

The trees allow us to break down the whole population and to focus on those subgroups which are at high risk for working poverty. For reasons of space, we present the results of just two trees (the others are annexed in the Appendix). We selected two, to some extent, extreme regions in Switzerland, i.e. Zurich and Ticino.

In Zurich (Figure 2) working poverty is primarily a matter of workers with elementary education living in couples with children, i.e. in large households. Here one out of five is a working poor. An intermediate educational level is not, however, a sufficient condition to escape working poverty when the size of the household is large and the total amount of working hours per week is less than 58 .

Ticino (Figure 3) is the region where working poverty affects people the most substantially. There, the rate of working poor is $7.1 \%$, compared to the mean national value of $4.5 \%$ (FSO). In Ticino working poverty is primarily a matter for workers living in large households, i.e. with five or more people. Here one person out of five is a working poor, and one out of three, if there are fewer than 1.5 full-time workers in the household. Amongst people living in a household of four, only foreigners are severely affected by the phenomenon. In smaller households working poverty becomes relevant only when connected with factors related to employment at a low salary (recently employed, employees without significant experience). Finally, a very specific group is that of foreigners with professional experience living in a household of three, especially if weekly working hours are fewer than 71 . 


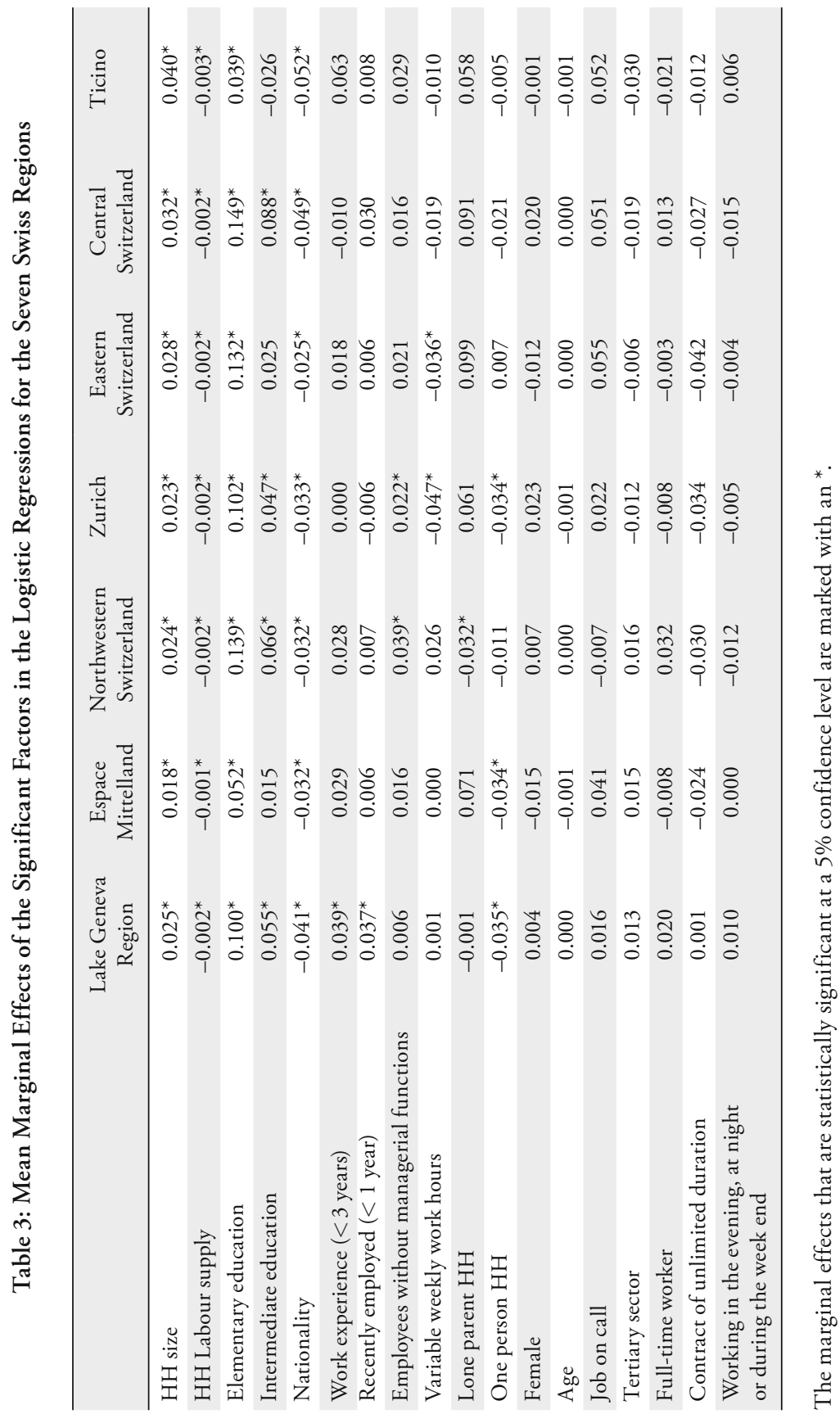


Figure 2: Classification Tree for Zurich

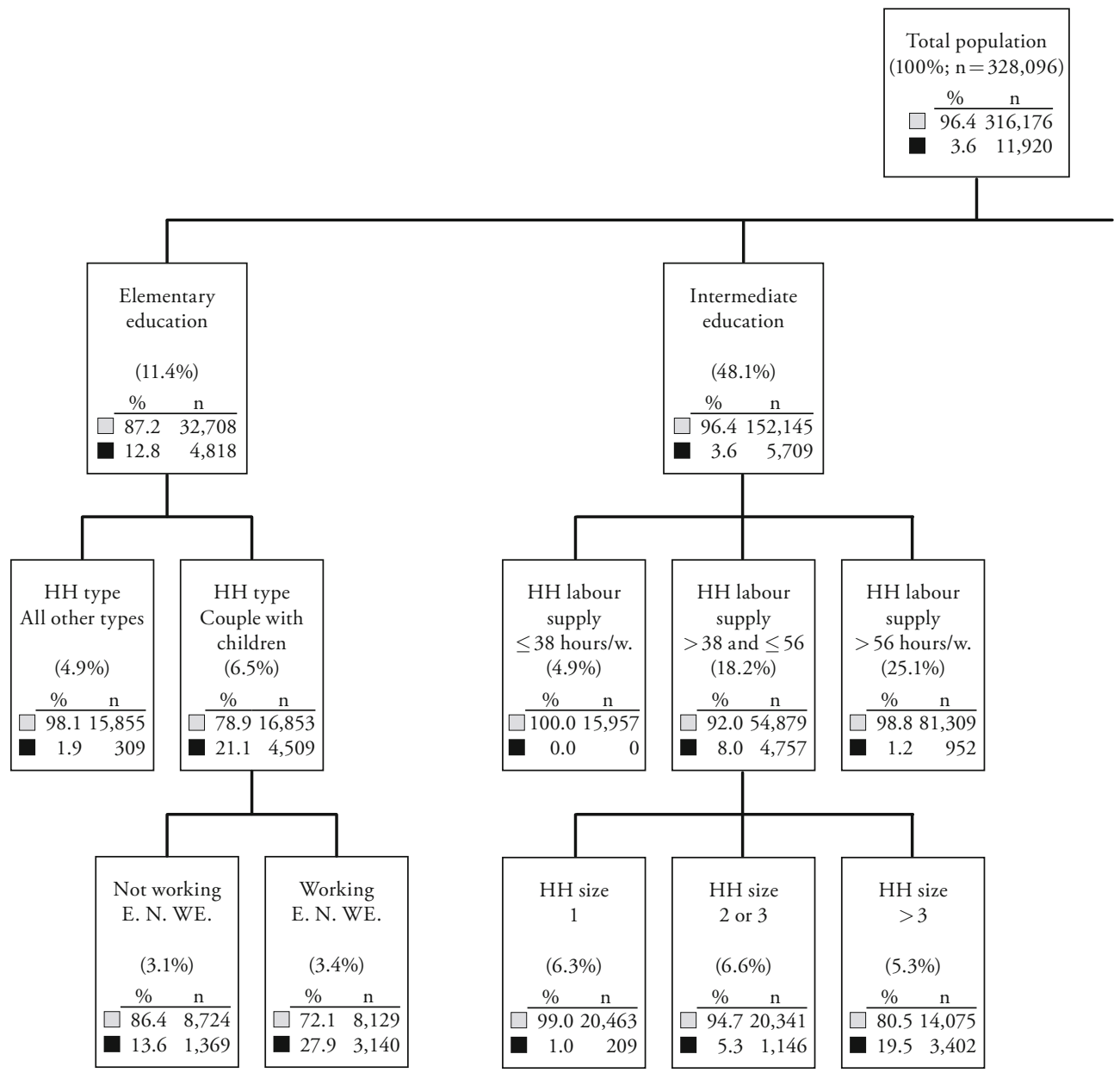

$\square \quad$ Non working poor

Working poor 


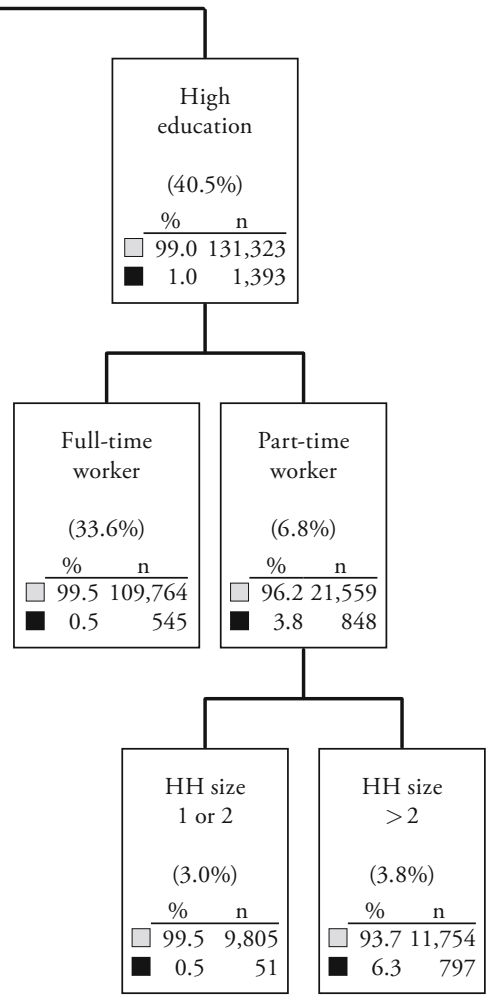


Figure 3: Classification Tree for Ticino

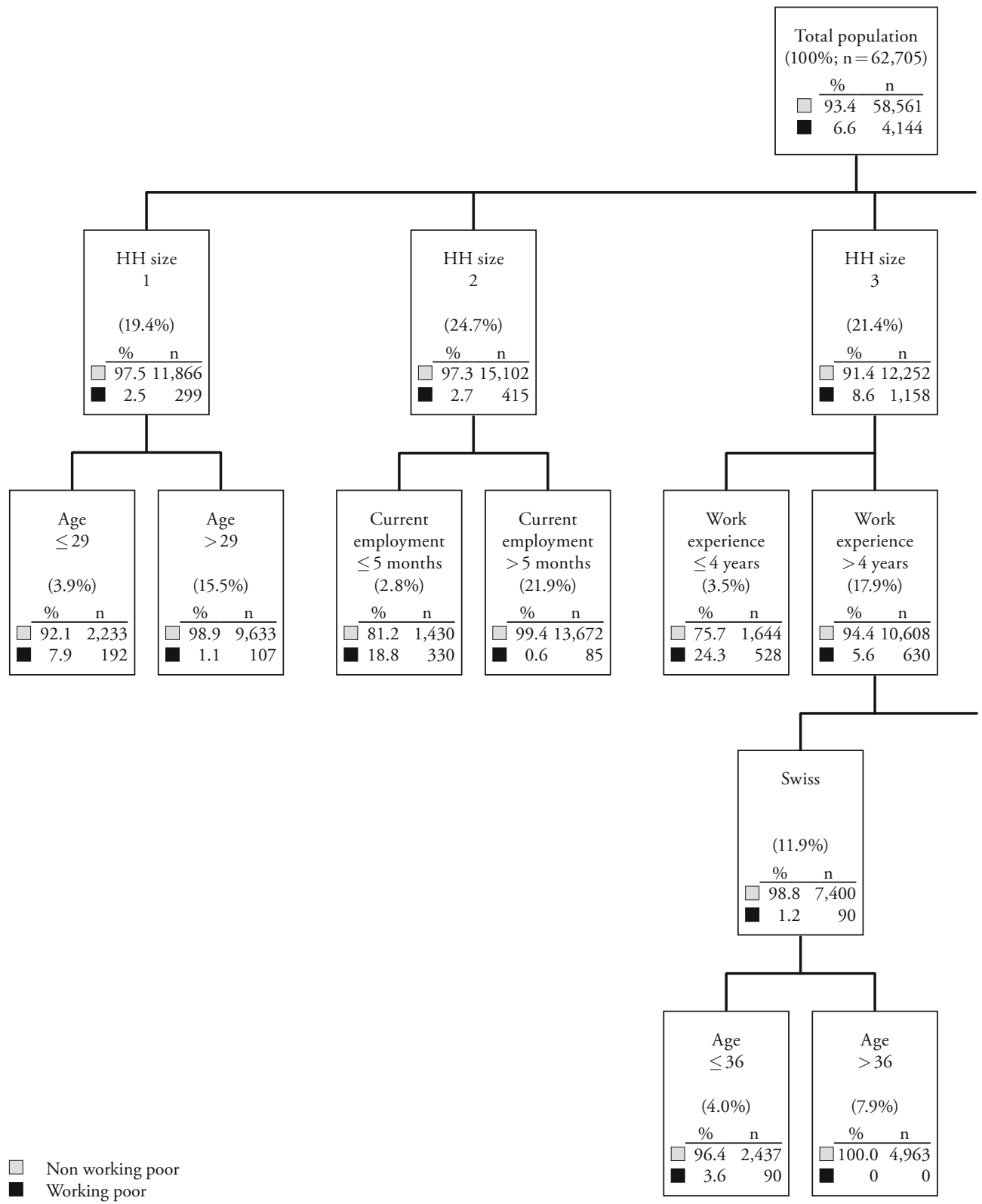



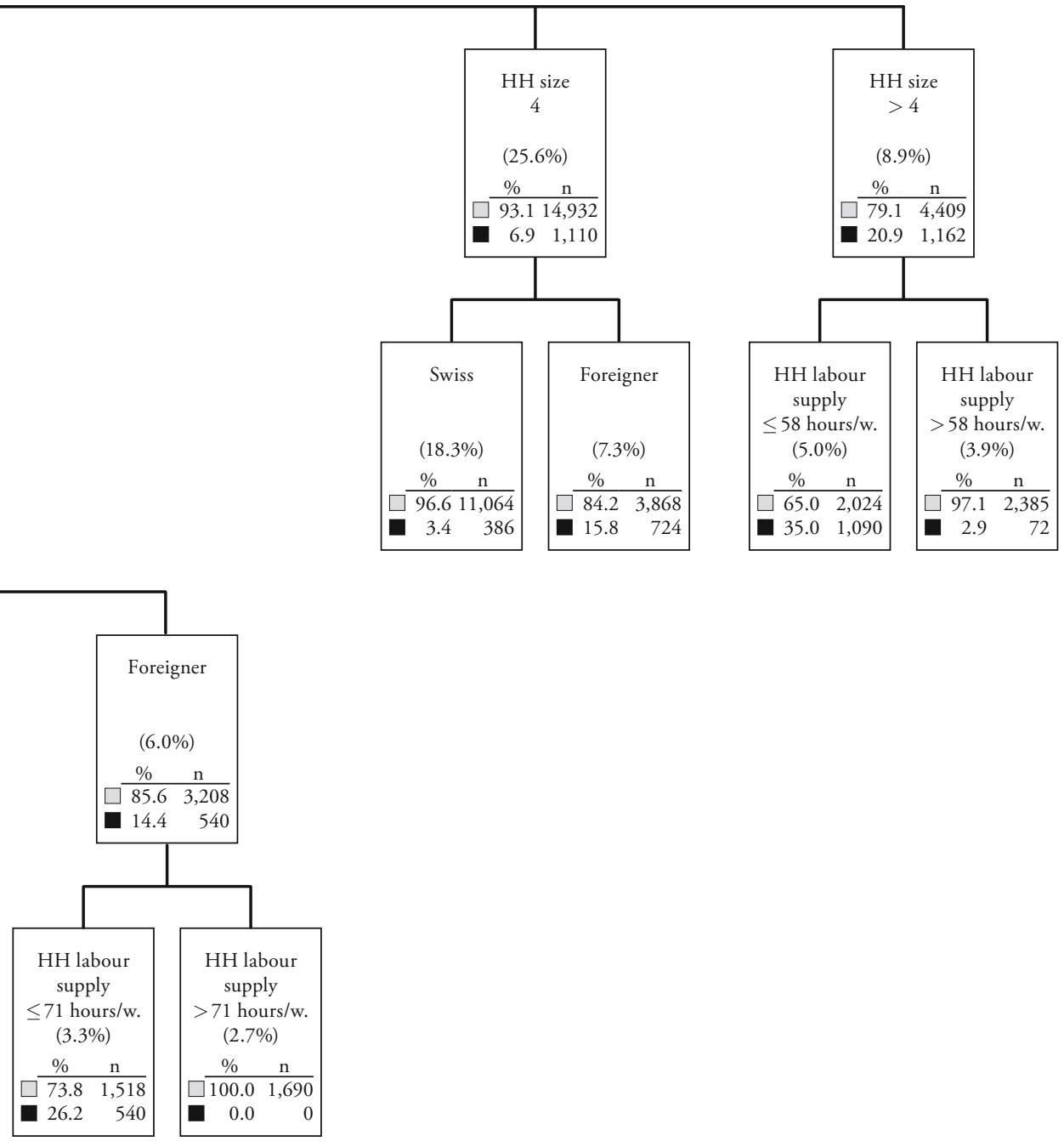


\section{Conclusions}

The analyses show that working poverty has basically the same nature and affects similar social groups across all Swiss regions.

This suggests that it might be reasonable to tackle the problem at a national level, looking for national policies (or a policy mix), or for a nationwide framework in which regional policies are developed.

In such a complex framework, characterised by a multifaceted problem which calls for multiple interventions and the involvement of different institutional levels, a critical condition is that policymakers properly understand both the issue at stake and the empirical findings. It is in this sense that here we have proposed to use logistic regression and classification trees. Apart from the reciprocally corroborative results, the combined use of the two methods enriches the understanding and interpretation of the phenomenon, thanks to the synergies that can be developed from their complementary aspects. One of the striking features of classification trees is that they provide results in a visual form, which enables straightforward interpretations by non-experts. This visual feature has exceptional advantages in terms of user-friendliness and in supporting the decision making process. A second important characteristic of the usefulness of classification trees in defining tailored policies is the clear partition of the whole population into target groups. On the side of logistic regression, its quantitative results are of major interest: they enable one to have a clear picture of the relationships between working poverty and its determinant factors, and they help to design and assess the efficiency of potential policies.

Though more and deeper research is necessary on this point, the experience gained in this research is very promising for future improvements in clarity of information and effective decision making.

As a last word, if we consider that there currently exist important differences in policies and institutional arrangements related to the factors of working poverty across Swiss cantons (for example in the fields of education, social security, family and work-life balance), the results are rather striking. We would have expected to find not only differences in the extent of the phenomenon (leading to the current differing regional working poor rates) but also in its structure (determinants). Is this a hint of the ineffectiveness of current regional policies and institutional arrangements? A question that calls for further research. 


\section{References}

Deutsch, Joseph, Yves Flückiger and Jacques Silber (1999), « «La population des bas salaires et des ‘working poor» en Suisse», in: Robert Fluder, Marion Nolde, Tom Priester and Antonin Wagner (eds), Comprendre la pauvreté pour mieux la combattre, Federal Statistical Office, Neuchâtel, pp. 247-275.

European Foundation for the Improvement of Living and Working Conditions (2004), Working Poor in the European Union, Luxembourg.

Evans, John M., and Ray K. Chawla (1990), "Work and Relative Poverty", Perspectives on Labour and Income, 2 (2).

Fabbris, Luigi (1997), Statistica multivariata. Analisi esplorativa dei dati, McGraw-Hill, Milan.

Falter, Jean-Marc (2006), "Equivalence Scales and Subjective Data in Switzerland”, Swiss Journal of Economics and Statistics, 142 (2), pp. 263-284.

Kass, Gordon V. (1980), "An Exploratory Technique for Investigating Large Quantities of Categorical Data", Applied Statistics, 29 (2), pp. 119-127.

Leu, Robert E., Stefan Burri and Tom Priester (1997), Lebensqualität und Armut in der Schweiz. Verlag Paul Haupt, Bern-Stuttgart-Wien.

Losa, Fabio B., and Emiliano Soldini (2006), Working but Poor in Ticino. Analisi statistica sulla base dei dati della Rilevazione sulle forze di lavoro del 2003. Aspetti statistici, Ufficio di statistica del cantone Ticino, Bellinzona.

OECD (2001), Employment Outlook, Paris.

Sharpe, Andrew (2001), "Estimates of Relative and Absolute Poverty Rates for the Working Population in Developed Countries", Paper presented at Meeting of the Canadian Economics Association, Montreal.

Streuli, Elisa, and Tobias Bauer (2002), Working Poor in der Schweiz. Konzepte, Ausmass und Problemlagen aufgrund der Daten der Schweizerischen Arbeitskräfteerhebung, Federal Statistical Office, Neuchâtel. 


\section{Appendix: Classification Trees for the Remaining Regions}

Figure 4: Classification Tree for the Lake Geveva Region

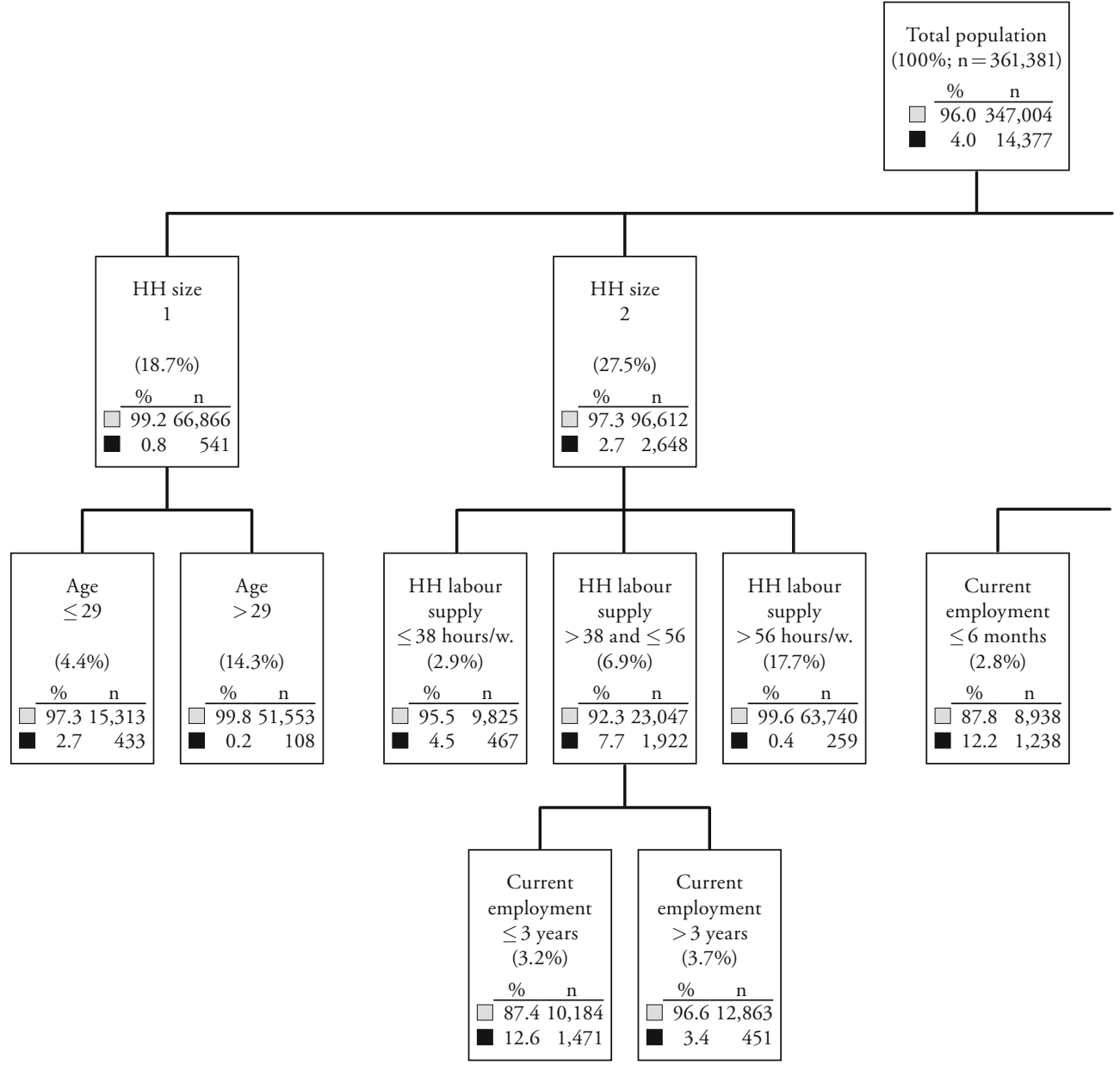




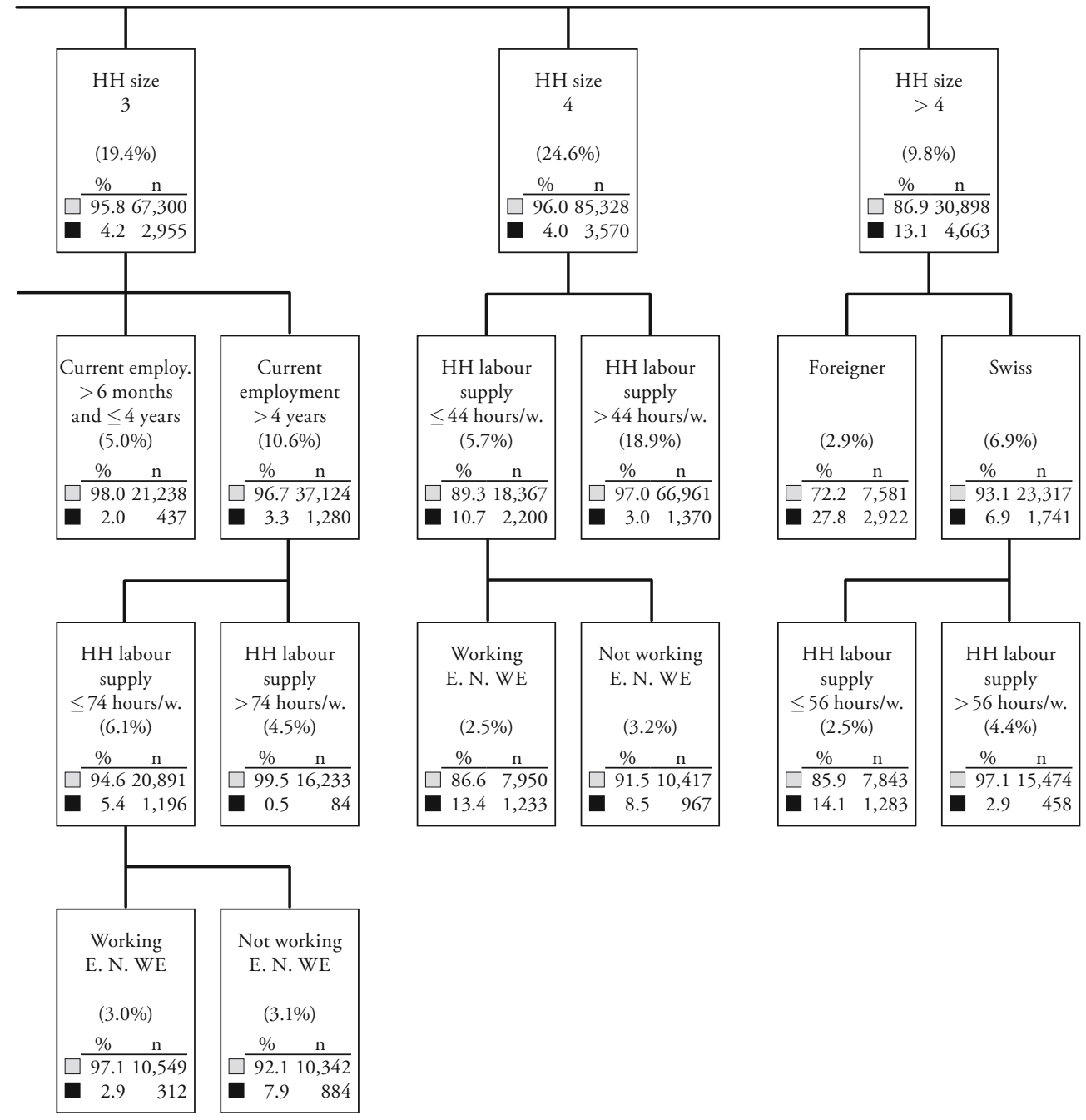


Figure 5: Classification Tree for Espace Mittelland

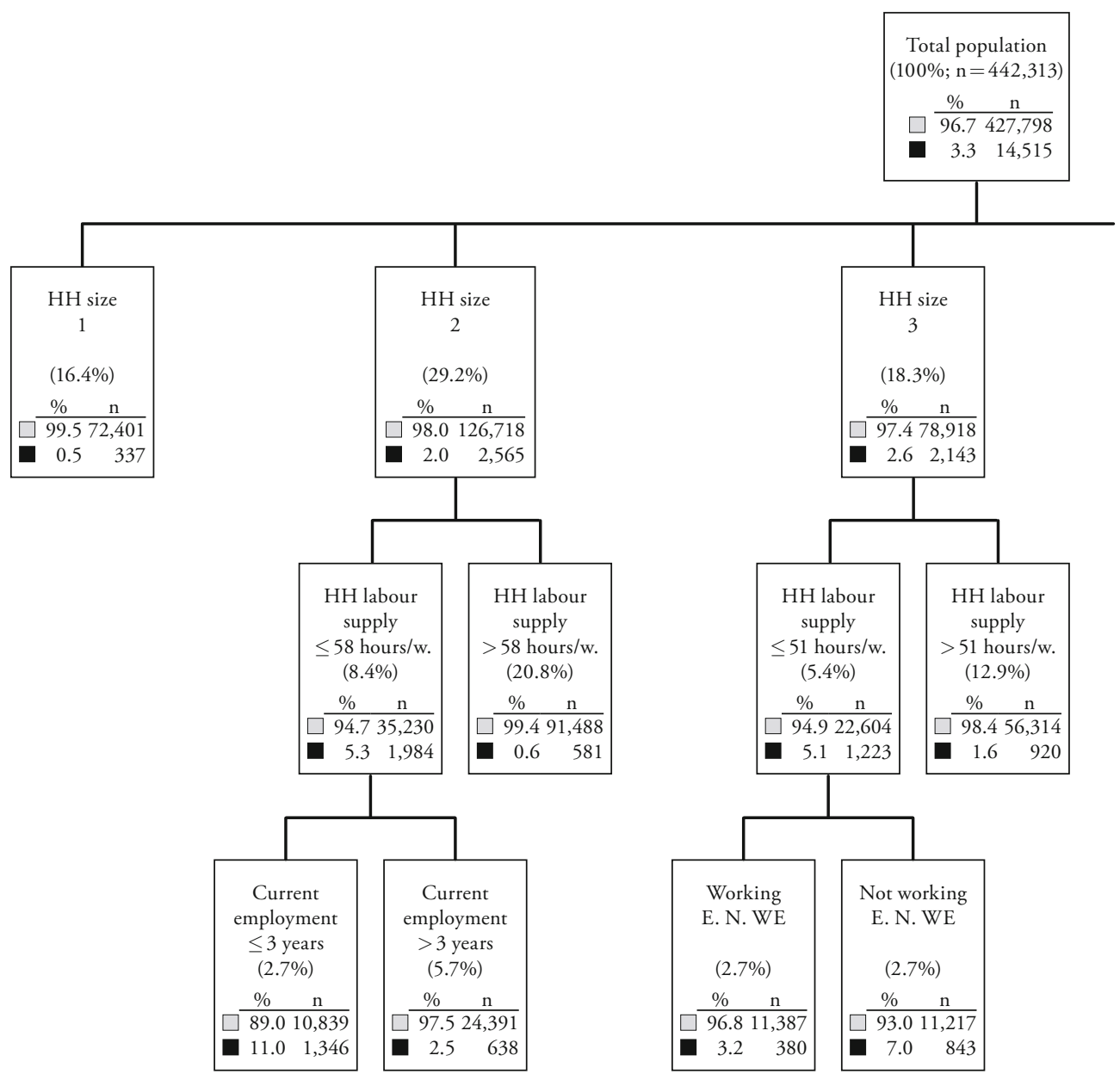

Working poor 


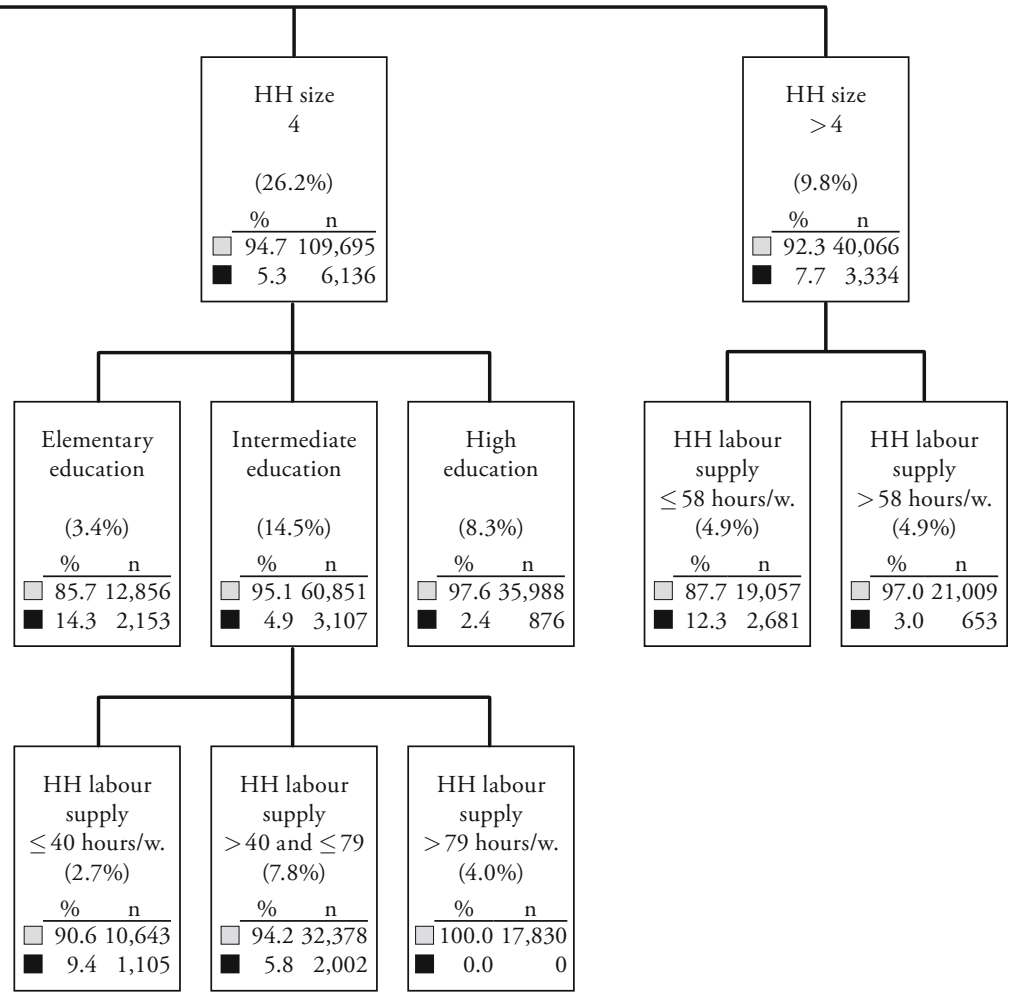


Figure 6: Classification Tree for Northwestern Switzerland

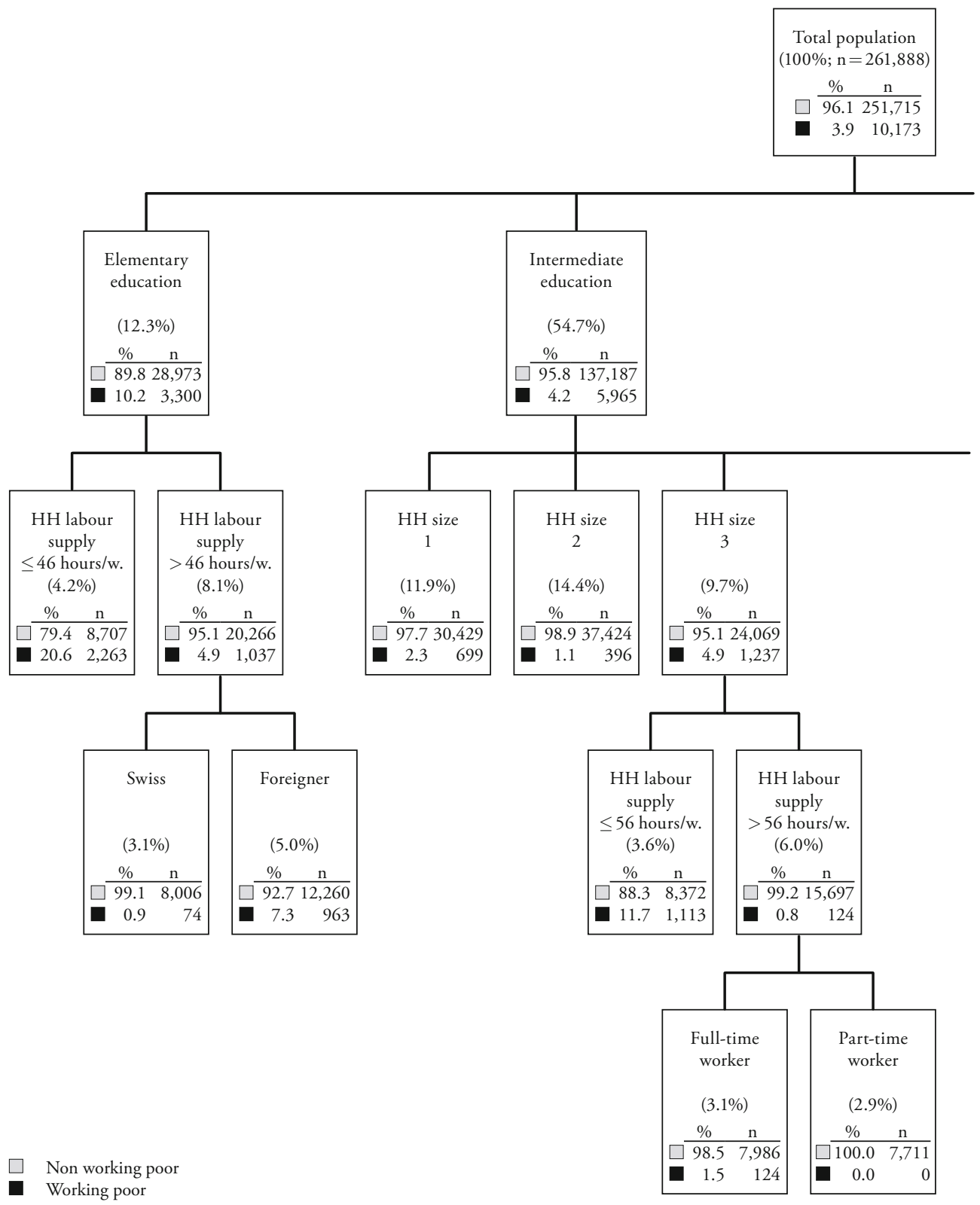




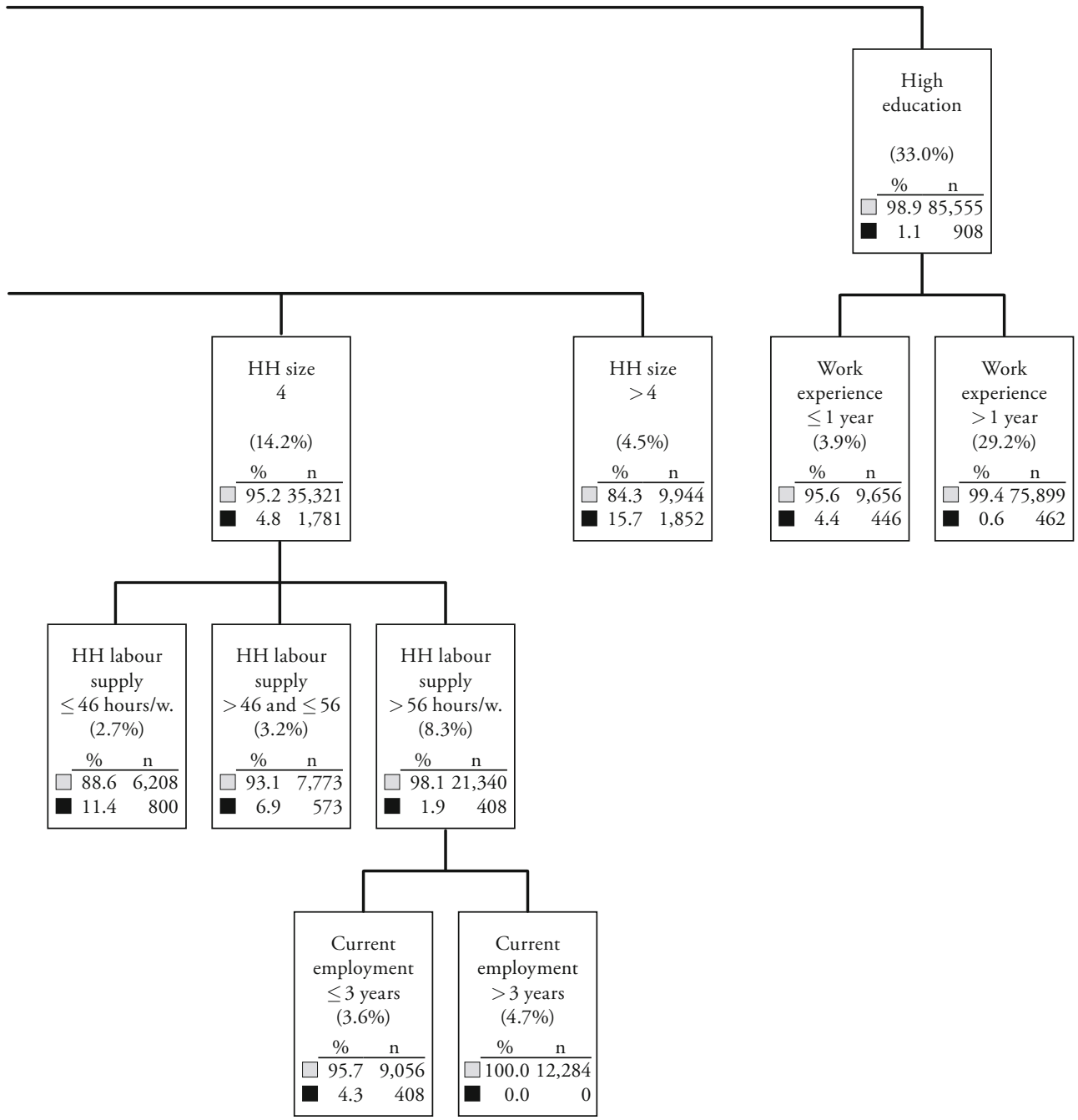


Figure 7: Classification Tree for Eastern Switzerland

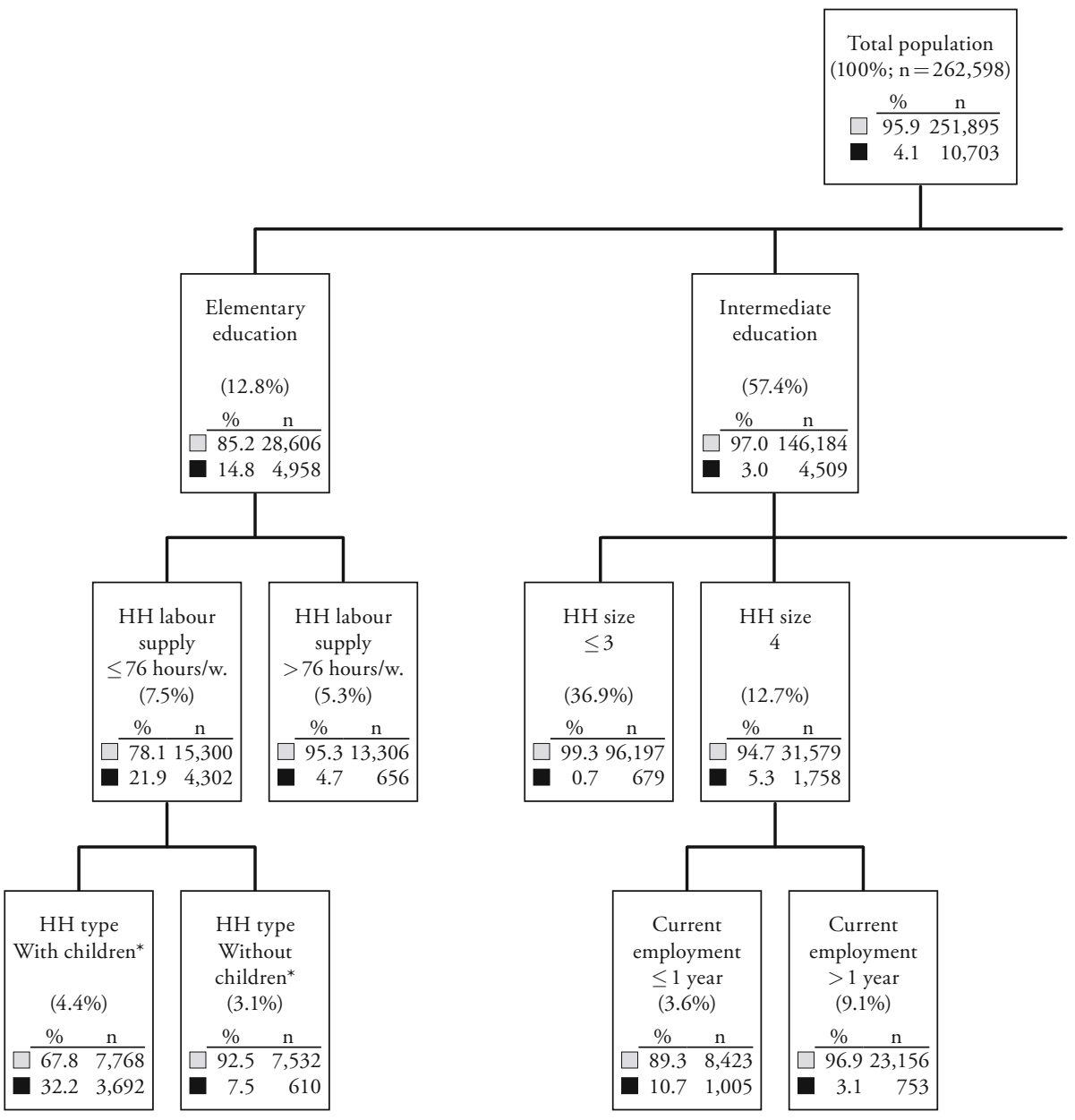

Non working poor

Working poor

* With children: couple with children, lone parent HH.

Without children: one person $\mathrm{HH}$, couple without children, other. 


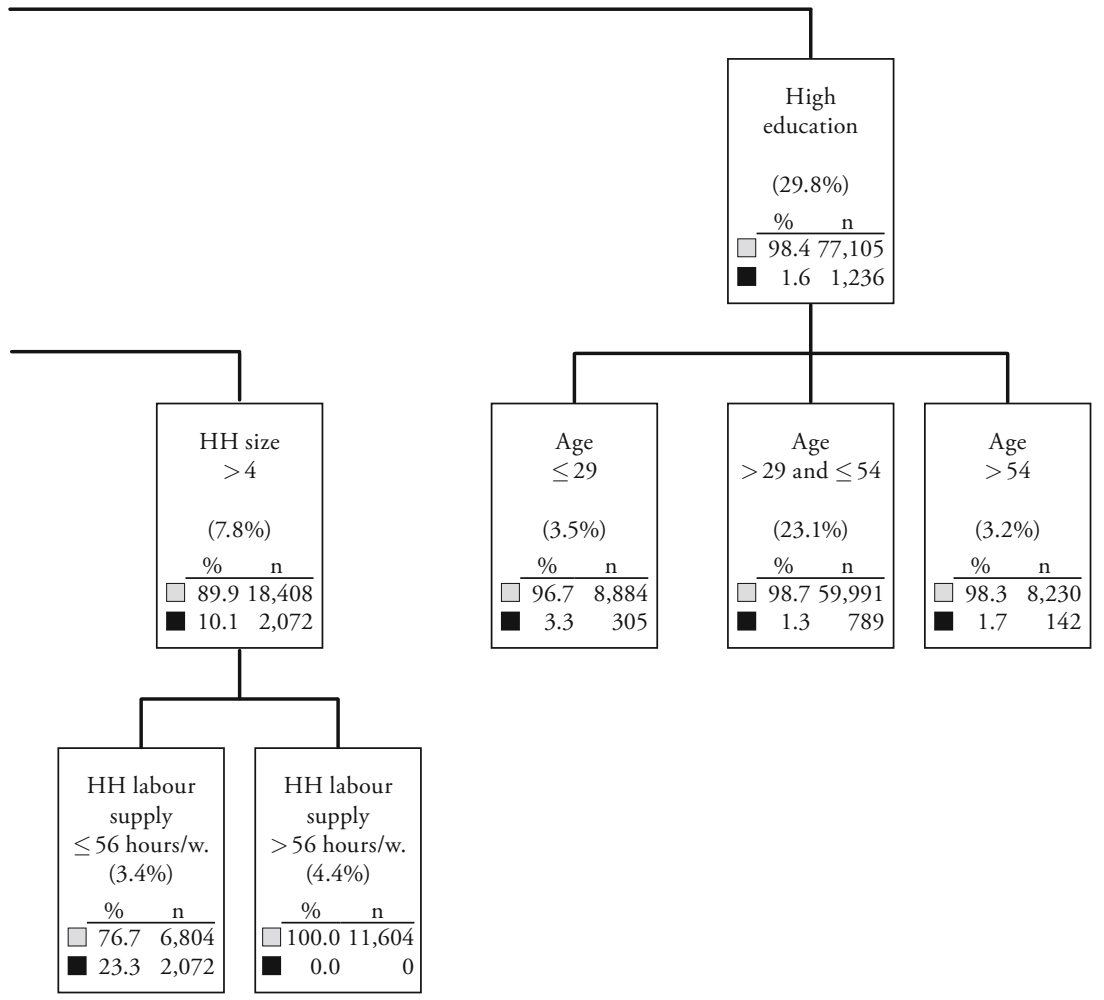


Figure 8: Classification Tree for Central Switzerland

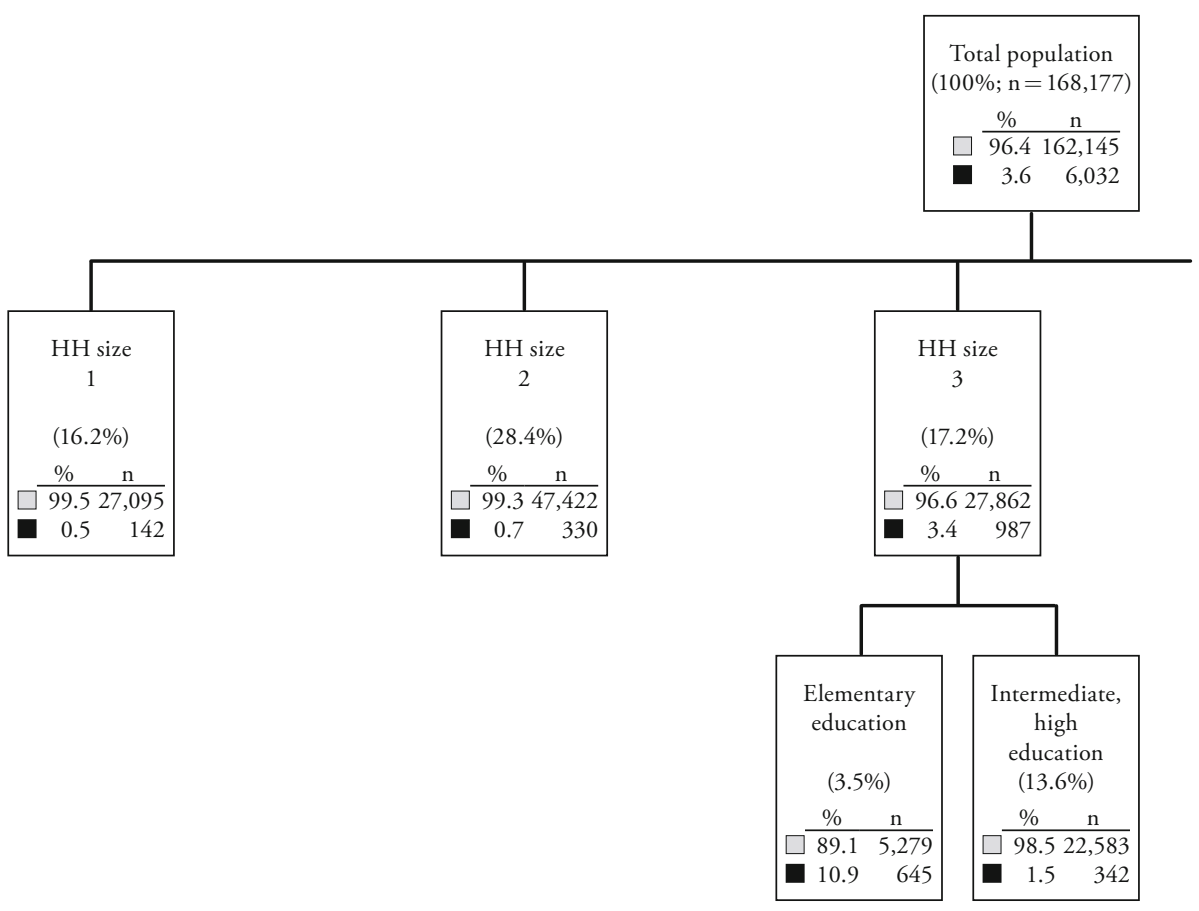

$\square \quad$ Non working poor

Working poor 


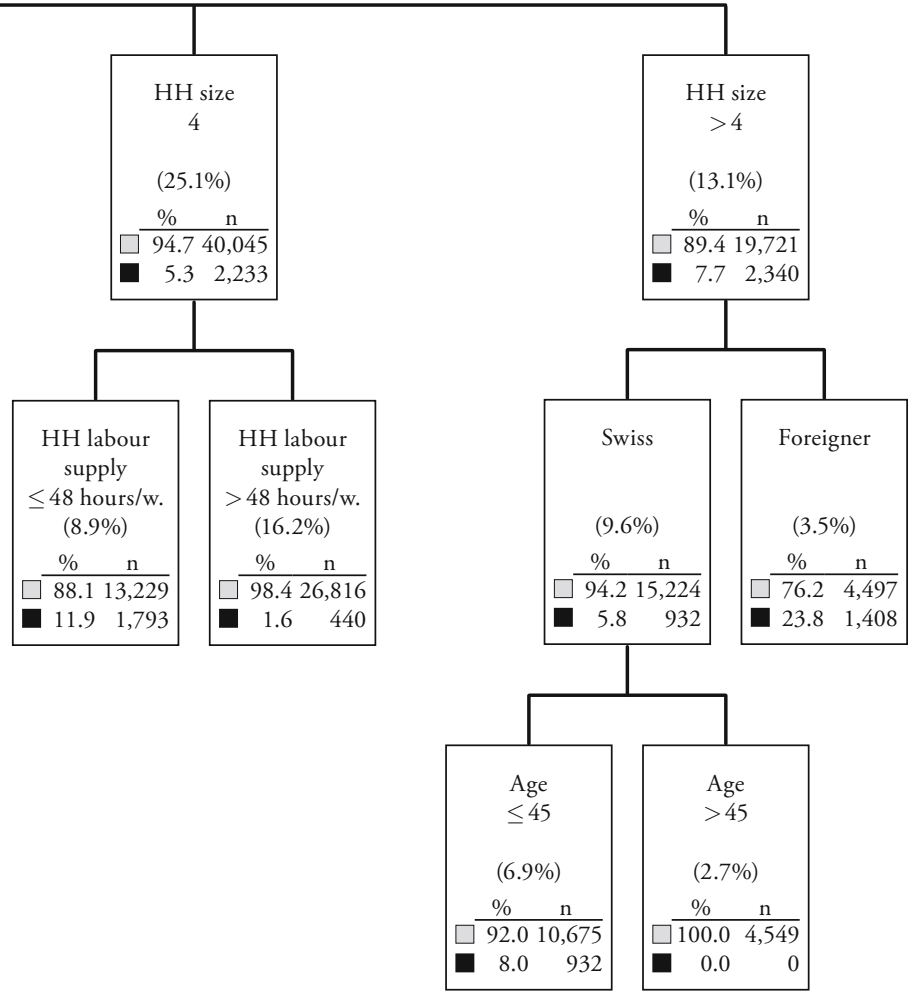




\section{SUMMARY}

This paper is an empirical investigation into working poverty across the seven statistical regions in Switzerland. By analysing, in a comparative setting, the determinants of the probability of falling below the poverty line and the resulting social groups at risk, the paper aims at shedding light on the existence of regional patterns and peculiarities which could call for regional policies rather than nationwide ones.

By using data from the Swiss Labour Force Survey of 2006, and adopting a definition of working poor as "people aged between 20 and 59 years who are working and who live in a working and poor household" and an absolute poverty line, data are analysed by two complementary methods - logistic regression and classification trees - in order to better assist policymakers in understanding the issues at stake and in the subsequent decision-making process. 